\title{
A BOTTOM-UP COST MODEL FOR ELECTRIC RAIL- BASED REGIONAL PUBLIC TRANSPORT SERVICES: THE ITALIAN CONTEXT
}

\author{
ALESSANDRO AVENALI $^{1}$, GIUSEPPE CATALANO ${ }^{1}$, TIZIANA D' ALFONSO ${ }^{1}$, MIRKO GIAGNORIO $^{1,2}$, \\ MARTINA GREGORI $^{1}$ \& GIORGIO MATTEUCCI ${ }^{1}$ \\ ${ }^{1}$ Department of Computer, Control, and Management Engineering - Sapienza University of Rome, Italy \\ ${ }^{2}$ Department of Mechanical and Aerospace Engineering - Sapienza University of Rome, Italy
}

\begin{abstract}
When comparing the cost structure of different transport operators, tools standardising the expenses an ideal efficient operator would incur in producing a specific transport service are valuable instruments for private companies and public authorities. In this paper, we build a bottom-up cost model for electric-driven rail-based regional transport services. The proposed model includes (i) transport services production costs; (ii) maintenance costs; (iii) administrative costs and (iv) the cost of capital. Except for the expenses for electric traction, infrastructure costs have been excluded and considered, as frequently happens, upon an external infrastructure manager. The bottom-up approach, relying on engineering analysis of the production process, limits the influence of past inefficiencies, typical of methods based on historical data. The model is developed for a generic short-medium distance service; it is then calibrated on the Italian context, thanks to disaggregating data on production collected through questionnaires from Italian transport operators in 2012 (covering 95\% of the national service).

We realised two settings, representing respectively an average performance and an 'ideal' best practise. To show the potentiality of the tool for policy makers, we apply the model to four case studies and calculate the maximum economic compensation paid to transport operators for each of them. The cases mainly differ over three fundamental characteristics: number of stops along the route, frequency and commercial speed. The latter two result to be the most influential factors in defining the unit standard cost. Finally, we run numerical simulations to measure the marginal impact on efficiency obtained by modifying selected cost-driving variables and highlight the most promising interventions to enhance the performance gains. In particular, we consider both elements under the control of operators (e.g. vehicles and drivers productivity) and elements under the control of public authorities (e.g. average fleet age). Keywords: bottom-up model, cost proxy models, local public transport, rail service, standard costs
\end{abstract}

\section{INTRODUCTION AND RELATED LITERATURE}

The transport services performance is difficult to assess, requiring complex and multi-perspective analysis (see [1] for recent reviews). Among all, the overall production costs represent a crucial element for the evaluation; nevertheless, when comparing the cost structure of different transport operators, an optimal benchmark is rarely available to look at as a reference. A tool standardising the expenses an ideal efficient operator would incur in producing a specific transport service would be a valuable instrument for private companies (e.g., identifying possible flaws or strengths in their production) and public authorities. Indeed, the definition of the maximum economic compensation in competitive tendering processes or the adequate financial subsidy that should be recognised to the transport operators in case of a direct award are challenging tasks. Rationalise those kinds of decisions, and supporting them with scientific data, would have a significant positive effect in optimising the use of the (scarce) public economic resources.

The concept of standard cost reflects the cost afforded by an efficient operator in producing a local public transport service (LTP), with a specified level of quality. The efficiency levels can be estimated statistically, based on the activities and costs of several operators (top-down 
approach), by building up the cost function of a specified service moving from the detailed knowledge of the industrial process (bottom-up approach) and/or by combining the above (hybrid approach). Spare works in previous literature have dealt with the specific definition and measurement of the standard cost of LTP services, mainly focusing on bus operations (e.g., [2-6]); while specific papers handled rail, metro and tram modes (e.g. [7-9]). Standard costs models were used by [10] to construct a benchmark tool to fairly compare transport mode options to serve a route and select the most preferable from the social welfare perspective (similar approach by [11]). Standard costs were explicitly adopted by the Italian Minister of Transport as criteria to assign public funds to the local authorities.

In this paper, we present a bottom-up model to determine the standard costs associated with the production of rail-based electric-driven regional public transports. Indeed, the rail-based modes, especially on medium-long distance connections, are signalled by the EU as a fundamental element to reach long-period sustainable transport systems, along with a progressive abandonment of diesel-traction for vehicles [12].

We estimate separately (i) operative transport costs; (ii) rolling stock maintenance costs; (iii) administrative and general costs; and (iv) the cost of capital. Notice that among the EU countries (including Italy), the regulation tends to formally separate infrastructure management and service production; in those systems, the infrastructure costs are made explicit in a toll, paid by the transport operators to have access to the network [13]. Thus, we decided to keep out altogether the infrastructure costs from the model (i.e. construction, activation, and maintenance), including in the perimeter just the expenses for the electric traction. We apply the proposed methodology to the Italian context, defining the standard costs for regional transport services (i.e. according to Italian regulation, this category refers to routes connecting at most two different regions). The calibration is performed employing disaggregated data collected in the Italian railways regional transport market in 2012. More updated data with similar coverage are not currently available. Future steps of this research work could be re-calibrate the model with more recent data. Eventually, we perform a simulation study to highlight the marginal impact of efficiency gains obtained by manipulating cost-driving variables.

The paper is organised as follows. Section 2 describe the cost model. Section 3 presents data and results with case studies and sensitivity analysis. Section 4 concludes.

\section{THE BOTTOM-UP PROXY COST MODEL}

Let us consider a regional rail electric-driven service $i$ in year $t$. We estimate separately: (i) standard cost of transport services production, $\bar{C}_{t r}$; ordinary maintenance for rolling stock standard costs, $\bar{C}_{\text {ord_man }}$; (iii) administrative and general standard costs, $\bar{C}_{\text {gen_adm }}$; and (iv) the standard cost of capital, $\bar{C}_{c a p}$. For the sake of readability, we use $\bar{C}_{t r}$ to indicate $\bar{C}_{t r, i, t}$ : the cost of service $i$ in year $t$; from now on, we apply the same conventional form to each cost component. The standard cost of electric regional railways services can be determined as:

$$
\bar{C}=\bar{C}_{t r}+\bar{C}_{\text {ord_man }}+\bar{C}_{g e n_{-} a d m}+\bar{C}_{c a p} .
$$

We can then derive the standard cost per train-revenue kilometre as:

$$
\bar{C}_{T R K}=\frac{\bar{C}}{T R K},
$$

where $T R K$ is the number of train*kilometres of run services, net of out-of-service operations. 


\subsection{The standard cost of transport services production}

The transport services production standard $\cos t \bar{C}_{t r}$ is a composite indicator:

$$
\bar{C}_{t r}=\bar{C}_{d r v_{-} c}+\bar{C}_{e l e_{-} t r a c}+\bar{C}_{r s}
$$

where:

- $\bar{C}_{d r v_{-} c}$ is the standard cost of personnel (drivers, train conductors, security staff);

- $\bar{C}_{\text {ele }}$ trac is the standard cost of traction power;

- $\bar{C}_{r s}$ is the standard cost of the rolling stock fleet.

The standard cost of the personnel

The estimation of this cost element requires the dimensioning of the driving personnel, train conductors and security staff. The overall costs are then calculated as follow:

$$
\bar{C}_{d r v_{-} c}=\bar{N}_{d r v} \cdot \bar{C}_{d r v, u}+\bar{N}_{d r v} \cdot \bar{N}_{c r e w} \cdot \bar{C}_{c r e w, u},
$$

where:

- $\bar{N}_{d r v}$ is the standard number of drivers;

- $\bar{N}_{\text {crew }}$ is a coefficient indicating how many train conductors and/or security staff for each driver are members of a vehicle's crew. Usually, average values for this parameter are $\{1,2,3\}$.

- $\bar{C}_{d r v, u}$ is the yearly standard unit cost for drivers;

- $\bar{C}_{c r e w, u}$ is the yearly standard unit cost for train conductors and security staff.

Notice that all cost of personnel also includes health and social insurance, and retirement funds. The standard number of drivers is estimated from the drivers' maximum gross hours of service and an overall production need, expressed in hours of in-service and out-of-service activities. Indeed, the calculation also takes into account the train*km produced in performing turnarounds at the end of the line or storing vehicles in depots:

$$
\bar{N}_{d r v}=\frac{T R K+T R K_{\text {out }}}{\overline{g H}_{d r v, u} \cdot\left(\operatorname{speed}_{c o m} \cdot \overline{A D J}_{s_{c o m}}\right)},
$$

where:

- $T R K_{\text {out }}$ is the number of train*kilometres produced out of service;

- $\overline{g H}_{d r v, u}$ is the standard number of gross driving hours per driver (i.e., standard driver's productivity). This parameter includes all hours spent driving for the service production, including train*kilometres produced out of service;

- speed $_{\text {com }}$ is the commercial speed, calculated as the ratio between total TRK and net driving hours (i.e., hours spent in driving);

- $\overline{A D J}_{s_{\text {com }}}$, usually with a value around 1 , is a conversion coefficient shifting the commercial speed to service speed (ratio between the train*km of overall activities performed in a unit gross hour of service - transport production and out-of-service activities, and the train*km of service produced in a unit hour of service). 
The standard cost of traction power

This cost item can be calculated as:

$$
\bar{C}_{\text {ele_trac }}=\left(T R K+T R K_{\text {out }}\right) \cdot \bar{C}_{\text {ele }, u},
$$

where:

- $\bar{C}_{e l e, u}$ is the unit standard cost of traction power (i.e., per kilometre), including train*kilometres produced out of service.

The standard cost of the rolling stock

This cost item refers to the expenses for the fleet acquisition. It can be calculated as:

$$
\bar{C}_{r s}=\bar{N}_{\text {train }} \cdot\left(\operatorname{Train}_{\text {cap }}\right) \cdot \overline{D E P R}_{\text {unit }},
$$

where:

- $\bar{N}_{\text {train }}$ is the standard number of trains used to provide the service;

- Train $_{\text {cap }}$ is the standard capacity used for the service provision, counting both available seats and standings options;

- $\overline{D E P R}_{\text {unit }}$ is the standard train depreciation per unit of capacity (either seat or standing option).

In particular, similarly to the process used to dimension the driving personnel, the standard number of trains used to provide the service can be calculated as follows:

$$
\bar{N}_{\text {train }}=\frac{T R K+T K_{\text {out }}}{\overline{\text { Train }}_{\text {prod }}},
$$

where:

- $\overline{\text { Train }}_{\text {prod }}$ is the standard number of train*kilometres produced per vehicle, including train*kilometres produced out of service and technical escorts (i.e., standard vehicle's productivity). The latter component can also measure the quality of service: higher technical escorts obviously correspond to less likely service interruptions and easier maintenance scheduling. Nevertheless, the technical escorts dimension could also be related to the delta requirements between service in the peak and service off-peak.

Notice that the parameter $\overline{D E P R}_{\text {unit }}$ takes into account standard depreciation of the rolling stock (including rents and leasing) as well as planned cyclical maintenance, which increases the book value of the asset (i.e. raises depreciation expenses in future periods). For this reason, such maintenance is capitalised.

2.2 The standard cost of ordinary maintenance

A significant cost item is related to the maintenance of rolling stock; it can be calculated as:

$$
\bar{C}_{\text {ord_man }}=\bar{N}_{\text {train }} \cdot \bar{C}_{\text {ord_man }, u},
$$


where:

- $\bar{C}_{\text {ord_man,u }}$ is the standard unit cost of ordinary vehicle maintenance (i.e. per train, and not per single car).

Vehicle maintenance includes the activities of cleaning, surveillance and assuring safety. Nevertheless, equipment and spare parts acquisition, labour for in-house maintenance, maintenance outsourced to third parties, machinery, and other fixed assets are usually the most significant costs components. It is worth mentioning that ordinary repairs are recorded as expenses in the current period, leaving the assets' book value unchanged.

2.3 The standard cost of administrative and general activities

The standard cost of administrative and general activities, $\bar{C}_{\text {gen_adm }}$, can be determined as:

$$
\bar{C}_{g e n \_a d m}=\left(\bar{C}_{t r}\right) \cdot \bar{C}_{g e n \_a d m, u},
$$

where:

- $\bar{C}_{\text {gen_adm,u }}$ is a measure of the standard incidence that general and administrative activities and assets costs have on total costs; it is represented as a percentage of the transport services production cost.

General and administrative activities and assets include, for example, economic planning and costs control, insurance contracts, business consulting and information systems, labour cost for the administration staff. In outline, any expenses other than those explicitly specified in our model are altogether included in this item.

\subsection{The standard cost of capital}

The last item we include in our bottom-up model is the standard cost of capital, corrected for the tax effects. The cost of capital refers to the minimum return on net invested capital that a private company needs to reward to all financial sources providers. According to our assumptions on the perimeter of costs and activities for the transport operators, it results that:

$$
\bar{C}_{c a p}=\bar{C}_{c a p_{r} r s},
$$

where:

- $\bar{C}_{c a p_{-} r s}$ correspond to the cost of capital invested in the rolling stock.

We then can calculate the cost item as:

$$
\bar{C}_{c a p_{-} r s}=W A C C_{r s} \cdot\left(\bar{C}_{r s} \cdot l_{r s}\right),
$$

where:

- $W A C C_{r s}$ is the Weighted Average Cost of Capital invested in rolling stock;

- $l_{r s}$ is the average age of vehicles. 


\section{DATA}

The proposed bottom-up model has been calibrated using certified micro-level economic data and actual transport services information about the Italian context. The disaggregated data cover costs, technical and environmental characteristics of the transport service production. They were collected in 2012 through questionnaires sent to Italian rail transport operators. The National Observatory, which monitors the transport industry performance, adopted the questionnaires' structure as a tool for the LPT policies.

The overall final database covers more than $217 \mathrm{mln}$ of train*km (of which $168.54 \mathrm{mln}$ of train*km from electrified lines), representing $96.23 \%$ of the Italian regional railways service production (see Table 1). Services appear to be mainly concentrated in the northern regions and, notably, in the central areas of Toscana and Lazio (both almost completely electrified; representing, respectively, $10.1 \%$ and $9.3 \%$ of the overall national services). The Lazio case is particularly interesting for the presence of Rome (a city with high territorial extension and high population density); it will be further investigated in the present paper as a case study to test the potentialities of the proposed model.

The database is used as a base to define the standard value for each cost driver required in our bottom-up model. In practice, we highlight three setups: a value interpolated from the data applying a linear trend to the observed data, a value representing the average level of efficiency observed among all the regional railways operators, and the value characterising the best performing operator (for the specific driver). Table 2 displays the standard values involved in evaluating the driving personnel costs, which also hints at the operators' performances. The incidence of revenue train* $\mathrm{km}$ over the total production, expressed by the coefficient $\overline{A D J}_{s_{\text {com }}}$, results to be essentially the same for a well-run operator and the benchmark, with a tendency in assuring high efficiency.

Table 1: Main characteristics of the models elaborated on the market.

\begin{tabular}{llll}
\hline Italian areas & Train*km observed & Train*km produced & \% coverage \\
\hline Northern areas & $112,199,293$ & $112,532,017$ & $99.70 \%$ \\
Central areas & $51,428,856$ & $53,579,796$ & $95.99 \%$ \\
Southern areas & $39,304,534$ & $45,339,759$ & $86.69 \%$ \\
Islands & $14,389,918$ & $14,389,918$ & $100.00 \%$ \\
Total & $217,322,604$ & $225,841,492$ & $96.23 \%$ \\
\hline
\end{tabular}

Table 2: Standards for the cost of the driving personnel.

\begin{tabular}{lllll}
\hline Cost driver & Coeff. linear reg. & Averagely efficient & Best performer & Coeff. of variation \\
\hline$\overline{A D J}_{s_{c o m}}$ & 0.9993 & 0.9985 & 1 & 0.0037 \\
$\overline{g H}_{d r v, u}$ & 594.55 & 652.53 & $1,077.31$ & 0.22 \\
{$\left[(\mathrm{~h} / \text { driver })^{*}\right.$ year $]$} & & & & \\
$\bar{C}_{d r v, u}[€ /$ driver $]$ & 63,035 & 60,672 & $41,285.71$ & 0.115 \\
$\bar{C}_{c r e w, u}[€ /$ staff $]$ & 52,893 & $52,878.56$ & $43,734.98$ & 0.074 \\
\hline
\end{tabular}


The economic cost of the rolling stock is tight to specific technological characteristics adopted for the fleet, including vehicles size and quality. On the latter, a firm could indeed have an incentive to invest in quality. The standardisation should then be able to avoid damaging distortions, such as the 'gold plating' of the fleet. To this end, we assume that $\overline{D E P R}_{\text {unit }}$ will represent an upper bound to the appliable depreciation, indicating a constraint on the new train procurement. The calculation of the $\overline{D E P R}_{\text {unit }}$ requires to specify (see Table 3 ): (i) a standard and fairly representative composition of the fleet; ii) the average market values (at 2012) for the specific needed vehicles, including the present value of the (capitalised) planned cyclical maintenance though their life cycle; (iii) the average vehicles' capacity (seats and standing options); (iv) the standard vehicles' productivity.

Notice that, since operators may use different depreciation periods for the fixed assets, the depreciation rate has been readjusted by considering a uniform depreciation period equal to 30 years. Therefore, the standard train depreciation per capacity unit (seats and standing options) is identified as follow: $\overline{D E P R}_{\text {unit }}=8,120,000 /(30 \times 1,069)=253.2 € /$ unit , where $€ 8,120,000$ is an average price for vehicles typically used to run regional services (e.g. Vivalto type, used by Trenitalia), in line with the market value indications made available by the Italian Government.

For cost categories other than the one associated with driving personnel remuneration and rolling stock acquisition, the distinction between the efficiency averagely showed by the operators and the one characterising the best performer is more pronounced (see Table 4). Finally, we compute the standard cost of capital assuming a pre-tax WACC of $6.23 \%$. This value is suggested for railways transport by the Italian Transport Regulation Authority [14].

Table 3: Standards for the cost of the rolling stock.

\begin{tabular}{|c|c|c|c|c|c|}
\hline \multicolumn{2}{|c|}{ Vehicles type } & $\begin{array}{c}\text { Seats } \\
\text { (with standings) }\end{array}$ & \multicolumn{2}{|l|}{$\begin{array}{c}\text { Price per vehicle } \\
(€)\end{array}$} & $\overline{D E P R}_{\text {unit }}$ \\
\hline $\begin{array}{l}\text { Electric-driven train } \\
\text { with } 5 \text { double-level }\end{array}$ & $\begin{array}{l}\text { set } \\
\text { carriages }\end{array}$ & $596(1,069)$ & $8,120,000$ & & 253.2 \\
\hline Vehicle productivity & Coeff. line & ar reg. Averagely effic & nt Best performer & Coeff. o & of variation \\
\hline $\begin{array}{l}\overline{\text { Train }}_{\text {prod }} \\
{[\mathrm{km} / \text { train }]}\end{array}$ & 115,801 & $107,681.22$ & $163,772.91$ & 0.2776 & \\
\hline
\end{tabular}

Table 4: Standards for the cost of the rolling stock.

\begin{tabular}{lllll}
\hline Cost driver & $\begin{array}{l}\text { Coeff. linear } \\
\text { reg. }\end{array}$ & $\begin{array}{l}\text { Averagely } \\
\text { efficient }\end{array}$ & Best performer & $\begin{array}{l}\text { Coeff. of } \\
\text { variation }\end{array}$ \\
\hline $\bar{C}_{p w r, u}[€ / \mathrm{Km}]$ & 0.29 & 0.53 & 0.21 & 1.148 \\
$\bar{C}_{\text {ord_man,u }[€ / \mathrm{Km}]}$ & 202,639 & $179,364.75$ & $80,036.01$ & 0.344 \\
$\bar{C}_{\text {adm_gen,u }}$ & 0.4016 & 0.4169 & 0.1548 & 0.345 \\
\hline
\end{tabular}




\section{RESULTS}

\subsection{Case studies}

This section shows how the proposed bottom-up model could be used by the public authorities at the micro-level to define a maximum economic compensation for the transport operators. We construct four case studies representing alternative settings for the regional railway services; the main relevant differences are due to the value assumed by the number of stops along the path, the rides' frequency and the commercial speed. Each case study is based on an actual route connecting Rome's city centre and relevant destinations in Lazio region. Table 6 collects the characteristics of the case studies regional railway services that we assume auctioned off by the public authority. For all the cases, we assume an average fleet age $\left(l_{r s}\right)$ of 15 years.

The number of stops actually performed along the path is a relevant indicator to identify the offered type of service; for example, it influences the service time performance (i.e. negative impact on the commercial speed), but at the same time, it positively affects the level of offered level of accessibility [15]. We distinguish between dedicated and multi-stops services. A high rides' frequency would too increase the accessibility while increasing at the same time production costs and complexity in management; we distinguish between low and high frequency. The commercial speed summarises the effects of the number of stops, tracks technical characteristics, and distance coverage. We distinguish between low speed, which could be associated with dense services (i.e. consecutive stops close to each other) rather than loose services (i.e. consecutive stops far from each other), and high speed. We represent dedicated services with either low frequency and commercial speed or high frequency and high commercial speed with the first and second cases (D-HF, D-LF). We represent multistops services with high frequency and low commercial speed or low frequency but high commercial speed with the third and the fourth cases (M-DS, M-LS).

Table 6 shows the result obtained applying our model to the case studies. Services run with relatively slow speed and relatively short distance appear more expensive to produce. The main factor is surely the low value of the commercial speed, limiting the efficient use of the fleet and the drivers. Indeed, the 'cheapest' unit standard cost of production is associated with the D-HF type of service, which presents the highest commercial speed in the sample. On the other hand, the most 'expensive' type of service to produce is the M-DS, which present specular drawbacks (most of all, a way smaller commercial speed).

Nevertheless, M-DS is also the service type with the greatest potential improvements in performance: the best performer efficiency gains reduce by $46.98 \%$ the trending average unit standard cost. The dedicated services present both a smaller distance between trending average and best performer unit standard cost of production.

We now examine the structure of costs associated with each case study, starting from the trending average performance settings. For all the service types, the most relevant cost element is the general and administrative costs category. Altogether, the D-LF type and the M-LS type presents the same structure (in order, rolling stock acquisition, cost of capital, drivers and maintenance). Instead, for the M-DS type the incidence of driver costs seems particularly high; this could be due to both the high frequency and the short travel time. Conversely, the incidence of drivers costs on D-HF type is not as significant as the rolling stockrelated expenses (due to the combination of the high number of rides and 'long' distance). 


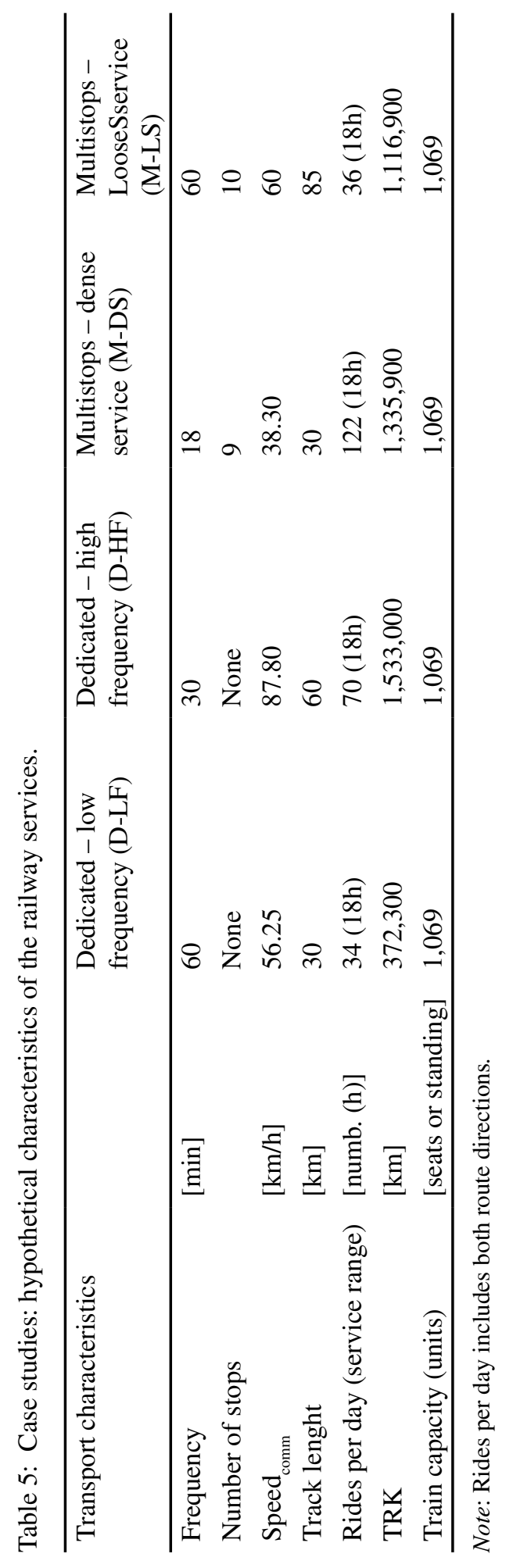




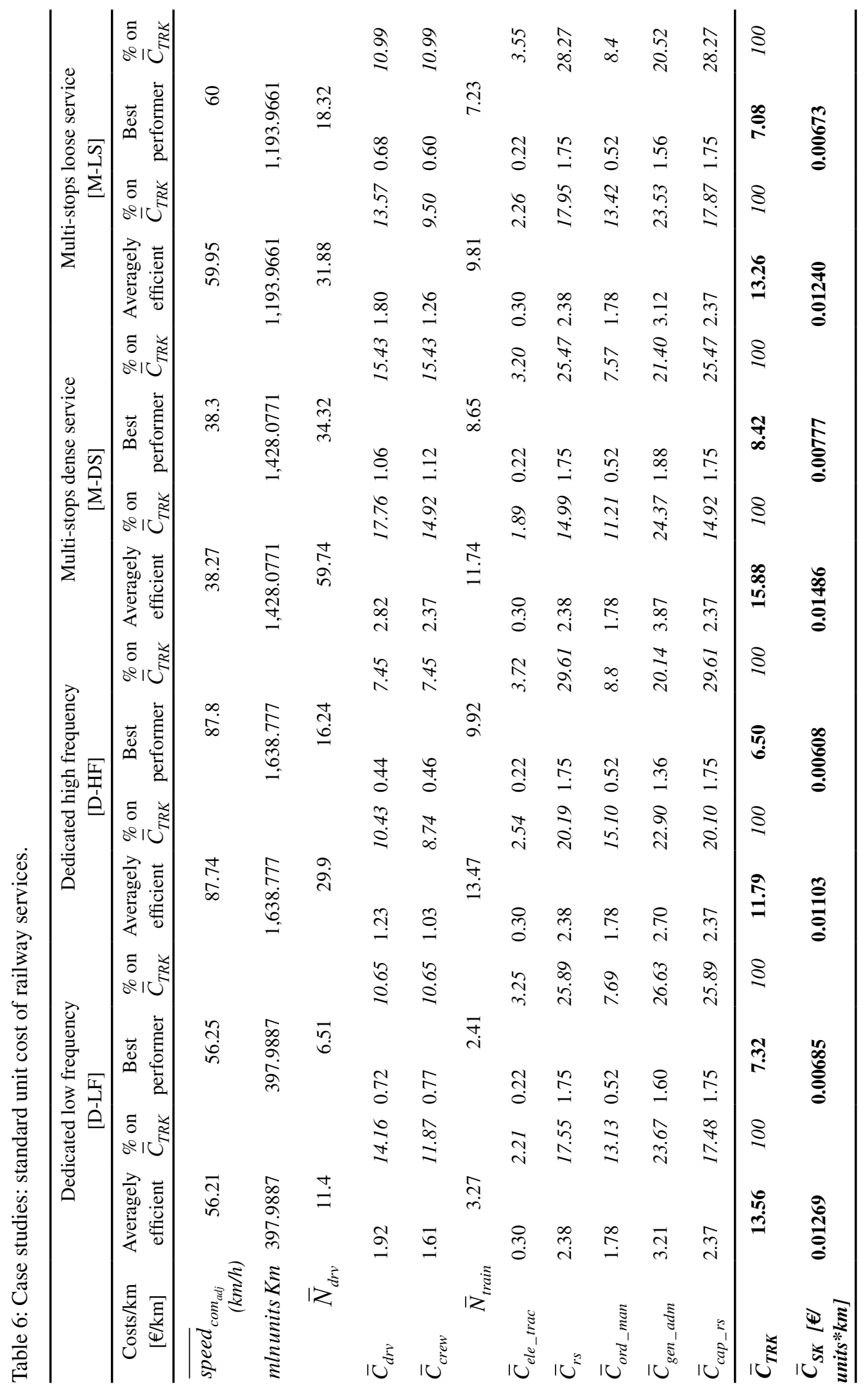


We now consider the best performer setting and verify how the structure of costs is not consistent. The most relevant cost elements for all the service types are the capital and rolling stock acquisition costs category, followed by general and administrative costs. M-LS, D-HF and D-LF types present the same structure of costs. The relative incidence of rolling stock maintenance costs significantly dropped, combined with a simultaneous reduction of the staff influence. D-HF type is on the same line of cost composition, even if, again, it appears to be mostly driven by the rolling stock category and presents more balance among the costs categories.

\subsection{Numerical simulations}

The public authorities entrusting the service, or the transport operators themselves in evaluating and updating their production, could set goals for a higher efficiency level. In this section, we show how the standard costs could vary according to those decisions. In other words, we measure the marginal impact on efficiency obtained by modifying selected cost-driving variables. For the sake of readability, we perform the numerical simulation considering the multi-stops loose case only. Figure 1 gives a graphical representation of the obtained results.

At first, we focus on cost-drivers that can be considered under the transport operators' control. In particular, we analyse the marginal impacts of changes in drivers and vehicles productivity (respectively, $\overline{g H}_{d r v, u}$ and $\overline{\text { Train }}_{\text {prod }}$ ), which we showed to be the most relevant factors in determining the standard costs. For each cost-driver, the impacts are measured always considering all other characteristics being fixed. The grey line in Fig. 1 shows the savings obtained when the gross driving hours per driver is progressively increased. For instance, a 5\%, 10\%, 20\%, 30\% increment in $\overline{g H}_{d r v, u}$ corresponds to, respectively, 0.22, 0.42 , 0.77 , and $0.1 .07 € / \mathrm{km}$ reduction on the unit standard costs. The maximum efficiency gain can be obtained by increasing the gross driving hours per driver by about $81 \%$, reaching the best performer value for the variable and savings equal to $2.08 € / \mathrm{km}$. The black line in Fig. 1 , analogously, shows the savings obtained when the maximum train*kilometres produced by a vehicle in a year are progressively increased. For instance, a 5\%, 10\%, 20\%, 30\% increment in $\overline{\text { Train }}_{\text {prod }}$ corresponds to, respectively, $0.39,0.75,1.37$, and $1.89 € / \mathrm{km}$ reduction on the unit standard costs. The maximum efficiency gain can be obtained by increasing the vehicles' productivity by about $41 \%$, reaching the best performer value for the variable and savings equal to $2.40 € / \mathrm{km}$. The lines slopes clearly exhibit how the interventions on the vehicles' productivity more effectively obtain efficiency gains. Indeed, the railways services are an asset-intensive business, rather than labour-intensive; this is despite the high incidence of drivers on total production costs. Overall, the acquisition and management of the rolling stock (including fleet use, traction power, train maintenance and cost of capital) account for about $40 \%$ of the total production costs.

We now focus on the public authorities role. The primary aspect of the transport production under PA control is the service dimensions, meaning the number of produced train*kilometres. According to the literature, railways production is characterised by economies of scale, with production systems obtaining cost advantages as infrastructure costs (which are mainly fixed and include activation, maintenance, station power and cost of capital) are covered over a larger scale of operation. Nevertheless, the economies of scale are accountable at the industry level; instead, the focus of the present paper is the transport production, in a context for which infrastructure costs are externalised altogether to a (not modelled) infrastructure manager. Hence, variations on the produced train*kilometres vary the overall standard production costs but do not particularly influence the unit standard cost $(€ / \mathrm{km})$. Public authorities can 


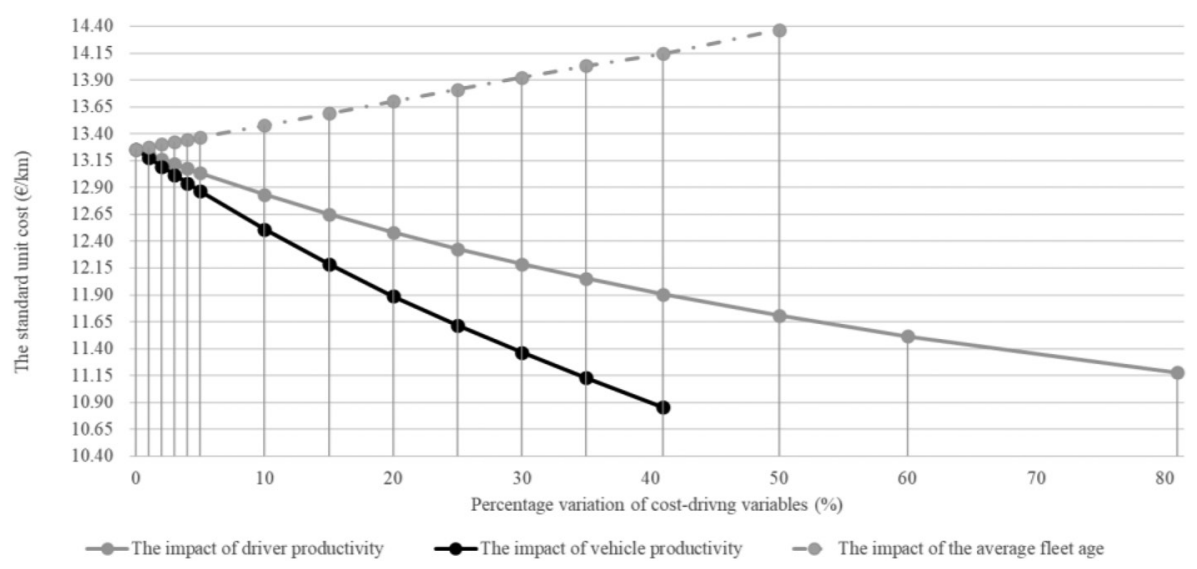

Figure 1: Efficiency gains/losses associated with variations in driver and vehicle productivity, and average fleet age.

also influence and/or impose specific characteristics for transport operators fleet. In particular, they can act on the average fleet age $\left(l_{r s}\right)$, for example, through public funds allocated for the purchase of new vehicles. The dotted grey line in Fig. 1 shows how progressive increments in the degree of rolling stock renewal (corresponding to a reduction in average fleet age, $l_{r s}$ ) negatively impact the costs of production. For instance, a 5\%, 10\%, 20\%, 30\% decrement in $l_{r s}$ corresponds to, respectively, $0.11,0.22,0.44$, and $0.67 € / \mathrm{km}$ increment on the unit standard costs. In fact, the periodic acquisition of new vehicles significantly affects the operators' net invested capital, hence capital cost. The latter simulation highlights how requests for increment in the quality of vehicles from public authorities (e.g. advanced infomobility systems, comfort, noise reduction) should also be supported with extra resources allocated to the operators.

\section{CONCLUSIONS}

Our paper proposes a standard cost model for electric-driven rail-based regional transport services. The model is calibrated on actual data collected in 2012 from transport operators active in the Italian context. We followed two settings: an average performer and an ideal best performer. We applied the model to four case studies, verifying that frequency and commercial speed are fundamental in dimensioning the unit standard costs. Eventually, numerical simulation were run to test marginal efficiency gains associated with selected cost-drivers changes and highlighted the most promising options to enhance performance. The obtained results could offer a valuable guide for the policy makers in defining the maximum economic compensation in competitive tendering processes or the adequate financial subsidy for the transport operators in a direct award. The lack of more updated data for the calibration could limit the representativeness of our results. Desirable future steps would be to apply the analysis on new datasets on the sector and add more drive-costs variables related to local paths characteristics (e.g. distance between consecutive stops, infrastructure costs expressed in tolling to access). 


\section{REFERENCES}

[1] Catalano, G., Daraio, C., Diana, M., Gregori, M., \& Matteucci, G., Efficiency, effectiveness, and impacts assessment in the rail transport sector: a state-of-theart critical analysis of current research. International Transactions in Operational Research, 26(1), pp. 5-40.

[2] Dalen, D.M. \& Lobo, A.G., Yardsticks on the road: regulatory contracts and cost efficiency in the Norwegian bus industry. Transportation, 30(4), pp. 371-386, 2003.

[3] Hensher, D.A., Mulley, C. \& Smith, N.A., Towards a simplified performance-linked value for money model as a reference point for bus contract payments. Research in Transportation Economics, 39(1), 232-238, 2013.

[4] Avenali, A., Boitani, A., Catalano, G., D’Alfonso, T. \& Matteucci, G., Assessing standard costs in local public bus transport: a hybrid cost model. Transport Policy, 62, pp. 48-57, 2018.

[5] Sansom, T., Nash, C., Mackie, P., Shires, J., \& Watkiss, P., Surface transport costs and charges. Institute for Transport Studies, University of Leeds, 2001.

[6] Cambini, C., Filippini, M., Piacenza, M., \& Vannoni, D., Corporatization and firm performance: evidence from publicly-provided local utilities. Review of Law \& Economics, 7(1), pp. 191-213, 2011.

[7] Avenali, A., Catalano, G., D’Alfonso, T., \& Matteucci, G., Standard cost of Italian metro services: the influence of automatism, wheels technology and capacity. WIT Transactions on the Built Environment, 182, 49-59, 2019.

[8] Avenali, A., Boitani, A., Catalano, G., Matteucci, G., \& Monticini, A., Standard costs of regional public rail passenger transport: evidence from Italy. Applied Economics, $\mathbf{5 2}$ (15), 1704-1717, 2929.

[9] Avenali, A., Catalano, G., D’Alfonso, T., Giagnorio, M., \& Matteucci, G., A proxy cost model for tramway services. International Journal of Transport Development and Integration, 4(4), pp. 353-367, 2020.

[10] Avenali, A., Catalano, G., Gregori, M., \& Matteucci, G., Rail versus bus local public transport services: a social cost comparison methodology. Transportation Research Interdisciplinary Perspectives, 7, 2020.

[11] Cambini, C., Piacenza, M., \& Vannoni, D., Restructuring public transit systems: evidence on cost properties from medium and large-sized companies. Review of Industrial Organization, 31(3), pp. 183-203, 2007.

[12] European Commission. A clean planet for all - a European strategic long-term vision for a prosperous, moder, competitive and climate neutral economy, 2018.

[13] Nash, C., Passenger railway reform in the last 20 years - European experience reconsidered. Research in Transportation Economics, 22(1), pp. 61-70, 2008.

[14] ART - Autorità di Regolazione dei Trasporti. Allegato A alla delibera n. 65/2020 del marzo 2020, 2020.

[15] Parbo, J., Nielsen, O. A., \& Prato, C.G., Reducing passengers' travel time by optimising stopping patterns in a large-scale network: a case-study in the Copenhagen Region. Transportation Research Part A: Policy and Practice, 113, 197-212, 2018. 